\title{
A retrospective analysis of early stoma complications
}

\author{
Valbona Bilali ${ }^{1}$, Ilirjana Zekja ${ }^{1}$, Ibrahim Bruka ${ }^{2}$, Helidon Nina ${ }^{3}$, Sokol Bilali ${ }^{2}$ \\ ${ }^{1}$ Faculty of Technical Medical Science, University of Medicine, Tirana, Albania \\ ${ }^{2}$ Department of General Surgery, University Hospital Center "Mother Teresa", Tirana, Albania \\ ${ }^{3}$ Department of Oncology, University Hospital Center "Mother Teresa", Tirana, Albania
}

Keywords: Stoma complication; malignancies; colostomy; ileostomy; stoma care

\begin{abstract}
\section{Introduction}

Colorectal cancer is among the most commonly occurring malignancies and it is often associated with a high morbidity and mortality rate. Although significant advances have been made in ostomy surgery since the late 1800s, early postoperative complications may still occur. This study aimed to determine the prevalence of early stoma complication in our surgery clinic.
\end{abstract}

\section{Methods}

In this paper, we studied 314 consecutive patients who were admitted to the hospital for stoma creation, as emergency or elective procedures.

\section{Results}

The most common indication for stoma creation was colorectal carcinoma. The more frequently used surgical interventions were low anterior resection with diverting (loop) ileostomy (161 patients, $51.2 \%$ ) followed by proximal defunctioning colostomy (54 patients, 17.2\%) and abdominal perineal resection with end colostomy (52 patients, 16.6\%). Ostomy-related complications developed in 121 patients $(38.5 \%)$.

\section{Conclusion}

Our findings indicated that early stoma complication rates were higher in patients with malignancies and permanent stomas.

\section{Introduction}

A stoma is a Greek word meaning "mouth or opening" [1]. The stoma is a surgically-created opening of the intestine (colostomy and ileostomy) or urinary tract (urostomy) on the front wall of the abdomen that allows the expulsion of faeces or urine from the body into a pouch or another collection

Correspondence: Sokol Bilali

E-mail: sbilali@hotmail.com

(i) https://orcid.org/0000-0001-6877-8378

Received: 16-01-2020 Accepted: 26-03-2021

DOI: http://doi.org/10.4038/sljs.v39i1.8693 device [2]. Colorectal cancer is among the most commonly occurring malignancies and it is often associated with a high morbidity and mortality rate. Unfortunately, colostomy continues to be the necessary treatment option in a large number of patients.

Although surgical techniques have evolved a lot, there is still a considerable occurrence of stoma complications. It's estimated that $25-60 \%$ of patients still suffer from complications. Such complications affect patient quality of life and increase the health care cost, as shown in prospective research and audits [3-7]. Stoma performance is a healthsaving or life-saving surgery most frequently performed between the 5 th and the 7 th decades of life.

The postoperative period can manifest many problems for stoma patients, including not only health problems but also psycho-emotional changes due to stress, financial costs, lifestyle changes, stoma bag adaptation etc.

Usually, these complications include superficial or deep stoma necrosis, dermatitis, mucocutaneous separation, retraction, bleeding, and parastomal abscess [8-11].

One of the immediate actions of the early postoperative period is the evaluation of the stoma. This assessment should focus on two aspects; first the possible complications of the stoma such as stomal necrosis, superficial and deep mucocutaneous separation, retraction and dermatitis and second the psycho-emotional evaluations of the patient and his adaptation to the new health situation.

Expected outcomes in the preoperative period included wellinformed patient, marked stoma site and a manageable level of anxiety.

The goal of our study was to analyze the prevalence of early stoma complications and classify the risk factors because only in this way we will be able to prevent them.

\section{Materials and Methods}

We collected and retrospectively analyzed the medical data of 314 consecutive patients who were admitted to the General Surgery Clinic at the University Hospital Center "Mother Teresa", in the period from January 2014 to December 2018. 
For all the patients included in the study are analyzed both, the data collections (gender, age, BMI, lifestyle, profession, heredity) and the history of comorbidities, history of the treatment of patients with chemotherapeutic preparations or use of radiotherapy sessions. Also considered type of stoma and if the stoma was temporary or permanent.

Before leaving the hospital, patients and their families are given a necessary instruction for home care, including diet, personal hygiene, the way of changing stoma bag, reducing strenuous physical activity by encouraging more walks in the fresh air to minimize the stress.

Despite the advice given, patients were usually seen at least two times during the first month following surgery, assessing and recording any expected changes or not of their health condition.

The follow-up of patients in this period was carried out also by a nurse stoma therapist.

Data were collected on a spreadsheet and entered into a software program (SPSS Inc., Chicago, IL). Data analysis was performed using SPSS 18 for Windows (SPSS Inc., Chicago, IL). All statistical tests were considered significant at $\mathrm{P}<0.05$.

\section{Results}

Our study included 314 patients, of whom 178 were female $(56.7 \%)$ and the remaining 136 patients were male (43.3\%). The mean age of patients taken in the study varies $53.5 \pm 15.4$ years. Of all the patients only $45(14.3 \%)$ had BMI $<18.5$ while 113 patients $(36 \%)$ had BMI 18.5 to $\leq 29.9$ and 156 patients (49.7\%) had a BMI $\geq$ of 30 . Table 1 presents the diagnoses of all the patients taken in our study. As can be seen from the table, the dominant diagnosis in patients who had a stoma, were colorectal carcinoma (249 patients, 79.3\%).

Table 1. Diagnosis of patients

\begin{tabular}{|c|c|}
\hline Diagnosis & $n(\%)$ \\
\hline $\begin{array}{l}\text { Elective operation for colorectal } \\
\text { carcinoma }\end{array}$ & $249(79.3 \%)$ \\
\hline Inflammatory bowel disease & $15(4.8 \%)$ \\
\hline Familial adenomatous polyposis coli & $4(1.3 \%)$ \\
\hline lleus due to colon carcinoma & $45(14.3 \%)$ \\
\hline Bowel perforation due to colon carcinoma & $1(0.3 \%)$ \\
\hline
\end{tabular}

Table 2. Types of surgical intervention

\begin{tabular}{|l|c|}
\hline \multicolumn{1}{|c|}{ Surgical Intervention } & $\mathbf{n}(\%)$ \\
\hline Anterior/low anterior resection + loop ileostomy & $161(51.2 \%)$ \\
\hline Low anterior resection + end colostomy & $54(17.2 \%)$ \\
\hline Abdominal perineal resection + end colostomy & $52(16.6 \%)$ \\
\hline Total colectomy + end ileostomy & $32(10.2 \%)$ \\
\hline Left hemicolectomy + end ileostomy & $9(2.9 \%)$ \\
\hline Right hemicolectomy + end ileostomy & $6(1.9 \%)$ \\
\hline Total & $314(100 \%)$ \\
\hline
\end{tabular}

Table 2 presents the types of surgical interventions for all patients included in our study. As seen from the table, the more surgical procedure used were Anterior / low anterior resection + loop ileostomy in 161 patients $(51.2 \%)$ Meanwhile, the least surgical procedure used were Right hemicolectomy + end ileostomy in only 6 patients $(1.9 \%)$.

Table 3. Distribution of early stoma complications

\begin{tabular}{|l|c|}
\hline \multicolumn{1}{|c|}{ Complications } & $\mathbf{n}(\%)$ \\
\hline Superficial mucocutaneous separation & $64(20.4 \%)$ \\
\hline Dermatitis & $29(9.3 \%)$ \\
\hline Retraction & $16(5 \%)$ \\
\hline Superficial necrosis & $7(2.2 \%)$ \\
\hline Deep mucocutaneous separation* & $5(1.6 \%)$ \\
\hline Total & $121(38.5 \%)$ \\
\hline
\end{tabular}

\# Separation of the stoma from skin up to fascia

Table 3 gives a more detailed overview of stoma complications assessed in the first 30 days after surgery. Based on the evaluation of the data, it is noted that stoma complications were found in 121 patients $(38.5 \%)$. The most common complication was Superficial mucocutaneous separation in 64 patients $(20.4 \%)$ and the least common was Deep mucocutaneous separation in only 5 patients $(1.6 \%)$.

Table 4 shows the distribution of complications in the patients with respect to age, gender, BMI, comorbidity, and undergoing neoadjuvant chemo/radiotherapy. As shown in table 4, stoma complications were observed more in malignant diseases $(33.8 \%)$ than in benign diseases $(4.7 \%)$. Meanwhile, it was noticed that cardiac pathologies (38.2\%) and diabetes mellitus (34\%) had a significant impact on the occurrence of stoma complications. Patients who underwent radiotherapy $(32.7 \%)$ were more at risk for stoma complications than those who underwent chemotherapy $(8.3 \%)$.

Also, stoma located in the right lower abdominal quadrant $(24.8 \%)$ were more significantly higher to that of those with stoma in the left lower abdominal quadrant (13.7\%). 
Table 4. Patient, surgery and stoma characteristics

\begin{tabular}{|l|l|c|c|}
\hline Variable & \multicolumn{1}{|c|}{ Category } & \multicolumn{2}{|c|}{ Complications } \\
\hline \multirow{3}{*}{ Gender } & & No & Yes \\
\cline { 2 - 4 } & Male & $95(30.3 \%)$ & $41(13 \%)$ \\
\cline { 2 - 4 } & Female & $119(37.9 \%)$ & $59(18.8 \%)$ \\
\hline \multirow{4}{*}{ Comolignancy } & Malignant & $189(60.2 \%)$ & $106(33.8 \%)$ \\
\cline { 2 - 4 } & Benign & $4(1.3 \%)$ & $15(4.7 \%)$ \\
\hline \multirow{3}{*}{ Stoma location } & Diabetes mellitus & $207(66 \%)$ & $107(34 \%)$ \\
\cline { 2 - 4 } & Cardiac disease & $194(61.8 \%)$ & $120(38.2 \%)$ \\
\cline { 2 - 4 } & Respiratory disease & $249(79.3 \%)$ & $65(20.7 \%)$ \\
\cline { 2 - 4 } & Left lower quadrant & $72(23 \%)$ & $43(13.7)$ \\
\hline \multirow{2}{*}{$\begin{array}{l}\text { Neoadjuvant } \\
\text { therapy }\end{array}$} & Radiotherapy & $68(40.5 \%)$ & $55(32.7 \%)$ \\
\cline { 2 - 4 } & Chemotherapy & $31(18.5 \%)$ & $14(8.3 \%)$ \\
\hline \multirow{3}{*}{ Type of stoma } & End Ileostomy & $33(10.5 \%)$ & $14(4.5 \%)$ \\
\cline { 2 - 4 } & End Colostomy & $32(10.9 \%)$ & $74(23.6 \%)$ \\
\hline
\end{tabular}

\section{Discussion}

Patients with colorectal cancer who undergo surgery and are subsequently left with a permanent ostomy deserve special attention. Besides the psychological impact of the malignancy, the stoma itself affects the patient in several ways.

The patients care in the preoperative period, according to the International Ostomy Association, should focus not only on physical preparation by clearly defining the side and location of the stoma but also on psychological preparation for what awaits the patients in the postoperative period $[12,13]$.

Another aspect impacting the quality of life in stoma patients involves skin issues, such as skin irritation (due to the close contact with stoma effluent) and the use of skin care products under the adhesive. However, if skin irritation is experienced, regular visits to the stoma care clinic could ensure optimal stoma skin management $[14,15]$. Studies focusing on the complications after ostomy surgery have shown complication rates between $21-70 \%$ and peristomal dermatitis was observed in several cases by Shabbir et al. [8]. Dermatitis is one of the stoma complications from frequent appliance changes were encountered in 29 patients $(9.3 \%)$. Park et al. reported that peristomal skin irritation ranges from 3 to $42 \%$ [16].

In our study, a significant number of early stoma complications were observed in 121 patients $(38.5 \%)$. In the study of Duchesne et al. [17] were reported $25 \%$ of 164 stoma patients while in another study, Robertson et al. [18] stoma complications were encountered in $23.5 \%$ of 408 stoma patients.

In terms of gender, women were more predisposed (18.8\%) to stoma complications than men (13\%). Ponczek et al. in their prospective study involving 3970 stoma patients, noticed a greater tendency of females for stoma complication than males [13].

Our study revealed that stoma complications were observed more in malignant diseases $(33.8 \%)$ than in benign diseases (4.7\%). Also, Nastro et al. had reported similar findings in their study [19].

In our study, it was found that the largest number of complications were in ileostomy than in colostomy, in 92 patients $(29.3 \%)$ vs 74 patients $(23.6 \%)$. These results can be attributed to a higher number of patients treated with an ileostomy than colostomy. While some retrospective and prospective studies have revealed reverse results, noticing a greater number of complications in colostomy than in ileostomy [20-22]. Among the types of ileostomy, it was noticed that complications in loop ileostomy were more frequent than end ileostomy, respectively 78 patients $(24.8 \%)$ vs 14 patients $(4.5 \%)$. The same findings have been observed in the study of Williams et.al.[23].

Previous studies have shown that the stoma site is another factor that affects stoma complications. In these studies, it is emphasized that the appropriate marking of the stoma site in the preoperative period is a necessary action that affects the minimization of stoma complications [16,24].

\section{Conclusion}

Our findings indicated that early stoma complication rates were higher in patients with malignancies, permanent stomas, and loop ileostomies. Radiotherapy conferred a higher risk for stoma complications than chemotherapy Meanwhile, the history of comorbidities like cardiac pathologies and diabetes mellitus had a significant impact on the occurrence of stoma complications. Prospective, randomized controlled studies are warranted to further elucidate the factors that influence stoma complication rates.

All authors disclose no conflict of interest. The study was conducted in accordance with the ethical standards of the relevant institutional or national ethics committee and the Helsinki Declaration of 1975, as revised in 2000 .

\section{References}

1. Burch J. The pre- and postoperative nursing care for patients with a stoma. Br J Nurs 2005; 14: 310-318

https://doi.org/10.12968/bjon.2005.14.6.17799 
2. Szewczyk J, Bajon A. Opieka pielegniarska w okresie okolooperacyjnym nad pacjentem $\mathrm{z}$ wyloniona stomia jelitowa. Pol Merkuriuz Lek 2009; 26; 575-8

3. Saghir JH, McKenzie FD, Leckie DM, et al. Factors that predict complications after construction of a stoma: a retrospective study. Eur J Surg. 2001;167(7):531-534 https://doi.org/10.1080/110241501316914911

4. Parmar KL, Zammit M, Smith A, Kenyon D, Lees NP. A prospective audit of early stoma complications in colorectal cancer treatment throughout the Greater Manchester and Cheshire colorectal cancer network. Colorectal Dis. 2011 ;13(8):935-938. https://doi.org/10.1111/j.1463-1318.2010.02325.x

5. Pittman J, Rawl S M, Schmidt C M, et al. Demographic and clinical factors related to ostomy complications and quality of life in veterans with an ostomy. J Wound Ostomy Continence Nurs. 2008;35(5):493-503

https://doi.org/10.1097/01.WON.0000335961.68113.cb

6. de Miguel Velasco M, Jiménez Escovar F, Parajó Calvo A. Current status of the prevention and treatment of stoma complications. A narrative review. [in Spanish] Cir Esp. 2014;92(3):149-156 https://doi.org/10.1016/j.ciresp.2013.09.011

7. Salvadalena GD. The incidence of stoma and peristomal complications during the first 3 months after ostomy creation. J Wound Ostomy Continence Nurs. 2013;40(4):400-406 https://doi.org/10.1097/WON.0b013e318295a12b

8. Shabbir J, Britton D C. Stoma complications: a literature overview. Colorectal Dis. 2010;12(10):958-964 https://doi.org/10.1111/j.1463-1318.2009.02006.x

9. Formijne Jonkers HA, Draaisma WA, Roskott AM, van Overbeeke AJ, Broeders IA, Consten EC. Early complications after stoma formation: a prospective cohort study in 100 patients with 1-year follow-up. Int J Colorectal Dis. 2012;27(8):10951099. https://doi.org/10.1007/s00384-012-1413-y

10.Lindholm E, Persson E, Carlsson E, Hallén AM, Fingren J, Berndtsson I. Ostomy-related complications after emergent abdominal surgery: a 2-year follow-up study. J Wound Ostomy Continence Nurs. 2013;40(6):603-610 https://doi.org/10.1097/WON.0b013e3182a9a7d9

11.Hendren S, Hammond K, Glasgow SC, et al. Clinical practice guidelines for ostomy surgery. Dis Colon Rectum. 2015; 58(4):375-387. https://doi.org/10.1097/DCR.0000000000000347

12. Charter of Ostomates Rights. United Ostomy Associations of America, Inc., Web site. http://www.uoaa.org/ostomy_info/ bill_of_rights.shtml. Published 2004. Accessed June 27, 2008.
13.Ponczek D, Nowicki A, Zegarski W. Evaluation of the quality of life of patients with rectal cancer resection or low anterior ventrolateral perineal excision without preoperative radiotherapy. Aspect Onkol 2005; 9:359-364

14.Ratliff CR, Scarano KA, Donovan AM, Colwell JC. Descriptive study of peristomal complications. J Wound Ostomy Cont Nurs 2005;32(1):33-37 https://doi.org/10.1097/00152192-200501000-00008

15.Liao C, Qin Y. Factors associated with stoma quality of life among stoma patients. International Journal of Nursing Sciences 2014;1(2):196-201.https://doi.org/10.1016/j.ijnss.2014.05.007

16. Park J J, Del Pino A, Orsay C P, et al. Stoma complications: The Cook County Hospital experience. Dis Colon Rectum. 1999; 42:1575-1580. https://doi.org/10.1007/BF02236210

17. Duchesne J C, Wang Y, Weintraub S L, Boyle M, Hunt J P. Stoma complications: a multivariate analysis. Am Surg. 2002; 68:961966

18.Robertson I, Leung E, Hughes D, et al. Prospective analysis of stoma-related complications. Colorectal Dis. 2005; 7:279-285 https://doi.org/10.1111/j.1463-1318.2005.00785.x

19.Nastro P, Knowles CH, McGrath A, Heyman B, Porrett TR, Lunniss PJ. Complications of intestinal stomas. Br J Surg. 2010;97(12):1885-1889. https://doi.org/10.1002/bjs.7259

20.Pokorny H, Herkner H, Jakesz R, Herbst F. Predictors for complications after loop stoma closure in patients with rectal cancer. World J Surg. 2006;30(8):1488-1493 https://doi.org/10.1007/s00268-005-0734-1

21.Rullier E, Le Toux N, Laurent C, Garrelon JL, Parneix M, Saric J. Loop ileostomy versus loop colostomy for defunctioning low anastomoses during rectal cancer surgery. World J Surg. 2001;25(3):274-277. https://doi.org/10.1007/s002680020091

22.Pine J, Stevenson L. Ileostomy and colostomy. Surgery (Oxford). 2014;32(4):212-217.

https://doi.org/10.1016/j.mpsur.2014.01.007

23.Williams NS, Nasmyth DG, Jones D, Smith AH. De-functioning stomas: a prospective controlled trial comparing loop ileostomy with loop transverse colostomy. Br J Surg. 1986;73(7):566-570 https://doi.org/10.1002/bjs.1800730717

24.Standards Development Committee of the United Ostomy Association National guidelines for enterostomal patient education. Dis Colon Rectum. 1994; 37:559-563 https://doi.org/10.1007/BF02050990 